\title{
Hereditary breast cancer and ancestry in the Madeira archipelago: an exploratory study
}

\author{
Isália Miguel ${ }^{1}$, Fátima Rodrigues ${ }^{1}$, Sofia Fragoso ${ }^{1}$, João Freixo ${ }^{2}$, Ana Clara ${ }^{1}$, Ana Luís ${ }^{1}$, Sandra Bento ${ }^{1}$, Mariana Fernandes ${ }^{3}$, Filipe Bacelar ${ }^{3}$, \\ Sara Câmara ${ }^{3}$, Joana Parreira ${ }^{1}$, Teresa Duarte ${ }^{1}$, Paula Rodrigues ${ }^{1}$, Sidónia Santos ${ }^{1}$ and Fátima Vaz ${ }^{1}$ \\ ${ }^{1}$ Instituto Português de Oncologia de Lisboa Francisco Gentil, EPE, Rua Prof. Lima Basto 1099-023 Lisboa, Portugal \\ ${ }^{2}$ CGPP-IBMC-i3S - Centro de Genética Preditiva e Preventiva, Instituto de Biologia Molecular e Celular, Instituto de Investigação e Inovação em Saúde, \\ Universidade do Porto, Rua Júlio Amaral de Carvalho 45, 4200-135 Porto, Portugal \\ ${ }^{3}$ Hospital Dr Nélio Mendonça, SESARAM, EPE, Avenida Luís de Camões 57, 9004-514 Funchal, Portugal
}

\begin{abstract}
Access to genetic testing and counselling in remote areas such as the Madeira archipelago, in the Northern Atlantic Ocean, may be complex. Different counselling methods, including telegenetics, should be explored. In this study, we characterise the Hereditary Breast/Ovarian Cancer (HBOC) families with Madeira ancestry enrolled in our programme. Of a total of 3,566 index patients tested between January 2000 and June 2018, 68 had Madeira ancestry and 22 were diagnosed with a pathogenic germline variant (PV). As in the whole group, BRCA2 PV were more frequent in Madeira patients (68.4\%: c.9382C >T (26.3\%), c.658_659del (21\%), c.156_157insAlu (10.5\%), c.793+1G>A (5.3\%) and c.298A $>T$ (5.3\%). However, the most frequently diagnosed PV in Madeira patients was the BRCA1 c.3331_3334del (31.6\%). BRCA1/2 detection rates were $27.9 \%$ and $10.5 \%$ for Madeira and the whole group, respectively. This study is the first characterisation of $\mathrm{HBOC}$ patients with Madeira ancestry. A distinct pattern of BRCA1/2 variants was observed, and the geographic clustering of BRCA1 c.3331_3334del variant may support the possibility of a founder mutation previously described in Northern Portugal. The high detection rate observed reinforces the need to reduce gaps in access to genetic testing in Madeira and other remote areas. According to current guidelines, timely identification of $\mathrm{HBOC}$ patients can contribute to their ongoing care and treatment.
\end{abstract}

Keywords: hereditary breast and ovarian cancer syndrome, founder effect, genetic testing, pathogenic variant

\section{Background}

The identification of pathogenic BRCA1 and BRCA2 variants has had a marked impact on cancer prevention and therapy, with criteria for BRCA1/2 testing being included in several cancer treatment and prevention guidelines [1-3]. Thus, the expansion of recommendations for BRCA1/2 testing has challenged established delivery models of care for access to genetic counselling and testing [1,4]. This access is even more complex
Correspondence to: Isália Miguel

Email: imiguel@ipolisboa.min-saude.pt

ecancer 2021, 15:1261

https://doi.org/10.3332/ecancer.2021.1261

Published: 05/07/2021

Received: 25/01/2021

Publication costs for this article were supported by ecancer (UK Charity number 1176307).

Copyright: ( $)$ the authors; licensee ecancermedicalscience. This is an Open Access article distributed under the terms of the Creative Commons Attribution License (http:// creativecommons.org/licenses/by/4.0), which permits unrestricted use, distribution, and reproduction in any medium, provided the original work is properly cited. 
in remote regions, where geographic limitations and lack of specialised programmes can negatively impact patient management and limit population-based genetic studies. Several models, including telegenetics, have been proposed to improve access to genetic testing without compromising quality of care [5]. These methods have not been found to be associated with long-term negative psychosocial outcomes [6].

In addition to targeted individual and family preventive and therapeutic management, knowledge of the geographical distribution of $B R C A 1 / 2$ variants is an important tool for population-based studies. Indeed, it represents one of the most useful ways to approach genetic variation and penetrance estimation and to clarify genotype-phenotype correlations. BRCA1 is described as the most frequently mutated gene in Hereditary Breast/Ovarian Cancer ( $\mathrm{HBOC}$ ) syndrome, but BRCA2 variants seem to be more frequent in the Portuguese population as well as in women of East Asian and Icelandic ancestry [7-9]. An excess of specific variants in certain populations has been associated with a founder effect, including in the Portuguese population, where BRCA2 c.156_157insAlu accounts for more than one fourth of the identified BRCA1/2 families [7, 10, 11]. Furthermore, other BRCA1 founder mutations have been described in HBOC families from North Portugal [7], but the distribution of $B R C A 1 / 2$ variants is unknown in the Madeira archipelago. There may be carriers of as yet undiagnosed founder variants in these islands, which are located nearly 1,000 km from continental Portugal in the North Atlantic Ocean [9-10, 12]. We reviewed all consecutive $\mathrm{HBOC}$ families with Madeira ancestry registered in our programme, explored their BRCA1/2 genotyping results and compared them with our data from continental Portugal.

\section{Methods}

\section{Ethics approval}

All procedures and consent forms were approved by the local Ethics Committee and all patients or their legal representatives signed an informed consent form.

\section{Patients \& methods}

In January 2000, a multidisciplinary HBOC programme was implemented in the Instituto Português de Oncologia de Lisboa. The objectives of this programme were the identification and risk management of $\mathrm{HBOC}$ patients. Initially, genetic testing was proposed for patients with a combined probability of at least $10 \%$ of having a BRCA1/2 pathogenic variant (PV), but the criteria for testing have been expanded over time, including patients without a family history of cancer (e.g. non-mucinous ovarian cancer after 2014) [13]. Paternal and maternal ancestry is recorded, up to the third previous generation. Pre-test and post-test counselling was done in person or by telephone. As of June 2018, a total of 5,925 index patients were enrolled in the programme and 3,566 consented to genetic testing (BRCA1/2:2,381 patients; multigene panel testing: 1,185 patients). The Madeira ancestry subgroup included 106 index patients (1.8\%) and 68 of them consented to BRCA1/2 testing, with four of them undergoing sequential TP53 (2) or PTEN (2) analysis. Nine patients consented to upfront multigene testing.

The cancer diagnoses of the index patients were mostly breast (86\%) and ovarian (9\%) cancer, with $1 \%$ having both diagnoses. In the Madeira subgroup, 60 patients (88\%) had breast cancer, six (8.8\%) had ovarian cancer, and two (2.9\%) had both. In this subgroup, eight patients had an additional cancer diagnosis (11.8\%).

All patients were tested for BRCA1/2 point variants, large rearrangements and the Portuguese founder variant in BRCA2 c.156_157insAlu [11]. Before the introduction of next generation sequencing (NGS), heteroduplex-based methods such as Conformational Sensitive Gel Electrophoresis [14-15] and Conformational Sensitive Capillary Electrophoresis [14-16] were used. From 2014 to 2018, BRCA1/2 point variants were analysed by NGS using the BRCA MASTR Dx kit (Multiplicom, Niel, Belgium) or multigene panels such as TruSight Cancer (IIlumina) or the BRCA Hereditary Cancer MASTR Plus kit (Multiplicom, Niel, Belgium) in a MiSeq platform (Illumina, San Diego, CA, USA) according to the manufacturer's protocol. Variant analysis was performed using DNAnexus software (CA, USA). All pathogenic or likely pathogenic variants were confirmed by Sanger sequencing. The genes tested in these panels included BRCA1, BRCA2, PALB2, CHEK2, PTEN, CDH1, TP53, ATM, RAD51C, RAD51D, BRIP1, RAD50, BARD1, NBN and BLM. 
Large deletions/insertions in BRCA1/2 genes were tested using Multiplex Ligation-dependent Probe Amplification (MRC-Holland, Amsterdam, The Netherlands) according to the manufacturer's protocol in an ABI Prism 3130 Genetic Analyzer platform (Applied Biosystems, Foster city, USA) and analysed using Coffalyser.Net software (MRC-Holland, Amsterdam, The Netherlands). Variants were named according to Human Genome Variation Society nomenclature guidelines (version 15.11) and the reference sequences of BRCA1/2, PALB2, ATM and RAD50 used are LRG_292t1, LRG_293t1, LRG_308t1, LRG_135t1 and NM_005732.3, respectively.

\section{Results}

A total of 3,566 patients were tested exclusively for BRCA1/2 (Table 1). Of these, 386 patients were diagnosed with a BRCA1/2 PV (19 with Madeira ancestry). Regarding other genes, 62 out of 1,185 patients had non-BRCA1/2 PV diagnosed, including 3 from the Madeira archipelago (Table 1). Detection rates, both for the entire programme and for the Madeira subgroup, were calculated considering only BRCA1/2positive results and were higher for the Madeira subgroup (27.9\% versus $10.5 \%$ ).

Table 1. Germline pathogenic variants identified in $\mathrm{HBOC}$ index patients from non-related families with Madeira ancestry.

\begin{tabular}{|c|c|c|c|c|c|c|c|c|}
\hline & \multirow{2}{*}{$\begin{array}{l}\text { Whole } \\
\text { registry }\end{array}$} & \multirow[b]{2}{*}{ Gene } & \multirow[b]{2}{*}{ Variant } & \multicolumn{2}{|c|}{ Madeira } & \multicolumn{2}{|c|}{$\begin{array}{c}\text { Whole registry(excluding } \\
\text { Madeira) }\end{array}$} & \multirow[b]{2}{*}{ Ethnicity/Nationality [31] } \\
\hline & & & & $\begin{array}{c}\text { Index } \\
\text { patients (n) }\end{array}$ & $\begin{array}{l}\text { Variant } \\
\text { frequency } ¥ \\
\quad(\%)\end{array}$ & $\begin{array}{c}\text { Index } \\
\text { patients (n) }\end{array}$ & $\begin{array}{l}\text { Variant } \\
\text { frequencyc } \\
\text { (\%) }\end{array}$ & \\
\hline \multirow{6}{*}{ 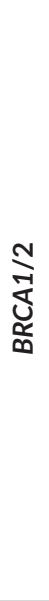 } & \multirow{6}{*}{$\begin{array}{l}3,566 \\
\text { patients } \\
\text { tested } \\
386 \\
\text { positive } \\
\text { index } \\
\text { patients }\end{array}$} & BRCA1 & $\begin{array}{l}\text { c.3331_3334del; } \\
\text { p.(Gln1111AsnfsTer5) }\end{array}$ & 6 & $\begin{array}{c}6 / 19 \\
(31.6 \%)\end{array}$ & 10 & $\begin{array}{l}10 / 367 \\
(2.7 \%)\end{array}$ & $\begin{array}{l}\text { European, Russian, Colombian, } \\
\text { Egyptian, Latin American, Caribbean, } \\
\text { Native American }\end{array}$ \\
\hline & & \multirow[t]{5}{*}{ BRCA2 } & c.156_157insAlu & 2 & $\begin{array}{c}2 / 19 \\
(10.5 \%)\end{array}$ & 86 & $\begin{array}{l}86 / 367 \\
(23.4 \%)\end{array}$ & Portuguese founder mutation \\
\hline & & & $\begin{array}{l}\text { c.298A>T; } \\
\text { p.(Lys100Ter) }\end{array}$ & 1 & $\begin{array}{c}1 / 19 \\
(5.3 \%)\end{array}$ & $0^{\mathrm{b}}$ & 0 & Central/Eastern European \\
\hline & & & $\begin{array}{l}\text { c.658_659del; } \\
\text { p.(Val220llefsTer4) }\end{array}$ & 4 & $\begin{array}{l}4 / 19 \\
(21 \%)\end{array}$ & $0^{\mathrm{b}}$ & 0 & $\begin{array}{l}\text { Japanese, South-East Poland, Norway, } \\
\text { European, African American, Lithuania, } \\
\text { Brazil }\end{array}$ \\
\hline & & & c. $793+1 G>A$ & 1 & $\begin{array}{c}1 / 19 \\
(5.3 \%)\end{array}$ & 12 & $\begin{array}{c}12 / 367 \\
(3.3 \%)\end{array}$ & None specified \\
\hline & & & $\begin{array}{l}\text { c.9382C>T; } \\
\text { p.(Arg3128Ter) }\end{array}$ & 5 & $\begin{array}{c}5 / 19 \\
(26.3 \%)\end{array}$ & $0^{b}$ & 0 & $\begin{array}{l}\text { Brazil, Norway, Chile; European, } \\
\text { African American, Latin }\end{array}$ \\
\hline \multirow{4}{*}{ 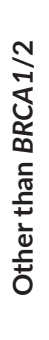 } & \multirow{4}{*}{$\begin{array}{l}1,185 \\
\text { patients } \\
\text { tested } \\
62 \\
\text { positive } \\
\text { index } \\
\text { patients }\end{array}$} & ATM & $\begin{array}{l}\text { c.8264_8268del; } \\
\text { p.(Tyr2755CysfsTer12) }\end{array}$ & $1^{\mathrm{a}}$ & - & 2 & $\begin{array}{c}2 / 59 \\
(3.4 \%) \\
\end{array}$ & Spanish, Brazilian \\
\hline & & \multirow[t]{2}{*}{ PALB2 } & $\begin{array}{l}\text { c.751C>T; } \\
\text { p.(Gln251Ter) }\end{array}$ & $1^{\mathrm{a}}$ & - & $0^{\mathrm{b}}$ & 0 & Chinese, German and Russian \\
\hline & & & $\begin{array}{l}\text { c.1633G>T; } \\
\text { p.(Glu545Ter) }\end{array}$ & 1 & - & $0^{\mathrm{b}}$ & 0 & German and Russian \\
\hline & & RAD50 & $\begin{array}{l}\text { c.2516_2517insA; } \\
\text { p.(Asp840ArgfsTer5) }\end{array}$ & 1 & - & 2 & $\begin{array}{l}2 / 59 \\
(3.4 \%)\end{array}$ & Latin \\
\hline
\end{tabular}

aThe same patient was diagnosed with both variants

bVariants diagnosed exclusively in the Madeira subgroup

cNumber of index patients with specific variant/total of index patients diagnosed with a PV in that cluster (BRCA1/2 or other than BRCA1/2) 
Nineteen germline BRCA1/2 pathogenic variants were identified in HBOC index patients from non-related families with Madeira ancestry (Table 1), with BRCA2 being the most frequently mutated gene (68.4\%). The c.3331_3334del in BRCA1 (31.6\%) and the c.9382C>T in BRCA2 (26.3\%) genes were the variants more recurrently identified. The c.3331_3334del BRCA1 was observed in six non-related families, being the only BRCA1 pathogenic event in this subgroup. The BRCA2 c.9382C >T, c.298A>T and c.658_659del variants were exclusively identified in patients with Madeira ancestry as well as the two PV in the PALB2 gene (c.751C>T and c.1633G>T).

\section{Cascade testing}

Within the 22 positive patients with a PV in the Madeira subgroup, a total of 59 family relatives were identified for cascade testing. All patients were given a detailed report so that local structures could identify additional relatives for testing and implementing risk-reducing measures in the case of carriers of pathogenic variants.

\section{Discussion}

This study reports the first characterisation of genetic variants associated with HBOC in patients with Madeira ancestry. We observed a higher-than-expected mutation detection rate and a pattern of $B R C A 1 / 2$ variant distribution different from the rest of the country, although, as expected for Portuguese HBOC patients, BRCA2 variants were diagnosed more frequently than BRCA1 [7, 17].

Regarding the higher detection rate observed for Madeira patients, selection bias cannot be excluded, since most of our index patients lived or travelled frequently to the continent, thus having easy access to genetic programmes that were not available at the time in archipelago. However, this observation deserves further analysis as, if confirmed, it highlights the potential positive impact on cancer prevention and treatment outcomes for breast and ovarian cancer patients in the archipelago.

When comparing the pattern of BRCA1/2 PV in the Madeira subgroup with that of the whole programme, a lower prevalence of the Portuguese BRCA2 founder variant (c.156_157insAlu) was observed in Madeira (10.5\% versus 23.4\%). Of the three BRCA2 variants only observed in Madeira patients (c.298A>T, c.658_659del and c.9382C>T), c.9382 C>T has been previously diagnosed in the North of Portugal [7].

The only BRCA1 PV identified in the Madeira subgroup (c.3331_3334del) was previously proposed to be a founder variant of Northern Portuguese origin [7]. This genetic event has also been observed in other populations such as Brazil [18-20], Colombia [21], Spain [22] and Canada [23]. Our data could add to the possibility of a founder effect, since up to $54 \%$ of the first XVI century settlements in Madeira originated from Northern Portugal. Haplotype analysis could help determine the possibility of a common ancestor.

The patients included in this study have had access to genetic testing for more than a decade, and panels and testing methods have evolved over time. The implementation of NGS testing has allowed the identification of mutant genes other than BRCA1/2 such as PALB2, ATM and RAD50 [24, 25]. The PALB2 variants (c.751C>T and c.1633G >T) were also exclusive to the Madeira subgroup, having previously been described in Portuguese, German, Russian and Chinese patients [26-28]. At this time, published evidence does not support the inclusion of RAD50 in hereditary breast and ovarian multigene panels [29, 30].

\section{Conclusions}

We observed a higher-than-expected detection rate and a distinct pattern of BRCA1/2 variants in HBOC patients with Madeira ancestry. Confirmation of BRCA1/2 variant distribution and further studies on geographic clustering of BRCA1 c.3331_3334del will add to our knowledge of population genetics. The observed high detection rate highlights the need to reduce gaps in access to genetic testing in Madeira and other remote areas. According to current guidelines, timely identification of HBOC patients may contribute to their ongoing care and treatment. 


\section{Conflicts of interest}

The authors declare that they have no conflict of interest.

\section{Funding declaration}

The author(s) received no specific funding for this work.

\section{References}

1. Vergote I, Banerjee S, and Gerdes AM, et al (2016) Current perspectives on recommendations for BRCA genetic testing in ovarian cancer patients Eur J Cancer 69 127-134 https://doi.org/10.1016/j.ejca.2016.10.006 PMID: 27821315

2. Daly MB, Pilarski R, and Yurgelun MB, et al (2016) NCCN guidelines insights: genetic/familial high-risk assessment: breast, ovarian, and pancreatic, version 1.2020 J Natl Compr Canc Netw 18(4) 380-391 https://doi.org/10.6004/jnccn.2020.0017 PMID: 32259785

3. Mohler JL, Antonarakis ES, and Armstrong AJ, et al (2019) Prostate cancer, version 2.2019, NCCN clinical practice guidelines in oncology J Natl Compr Canc Netw 17(5) 479-505 https://doi.org/10.6004/jnccn.2019.0023 PMID: 31085757

4. Kemp Z, Turnbull A, and Yost S, et al (2019) Evaluation of cancer-based criteria for use in mainstream BRCA1 and BRCA2 genetic testing in patients with breast cancer JAMA Netw Open 2(5) e194428 https://doi.org/10.1001/jamanetworkopen.2019.4428 PMID: 31125106 PMCID: 6632150

5. Kinney AY, Steffen LE, and Brumbach BH, et al (2016) Randomized noninferiority trial of telephone delivery of BRCA1/2 genetic counseling compared with in-person counseling: 1-year follow-up J Clin Oncol 34(24) 2914-2924 https://doi.org/10.1200/JCO.2015.65.9557 PMID: 27325848 PMCID: 5012661

6. Zierhut HA, MacFarlane IM, and Ahmed Z, et al (2018) Genetic counselors' experiences and interest in telegenetics and remote counseling J Genet Couns 27(2) 329-338 https://doi.org/10.1007/s10897-017-0200-x PMID: 29362948

7. Peixoto A, Santos C, and Pinto P, et al (2015) The role of targeted BRCA1/BRCA2 mutation analysis in hereditary breast/ovarian cancer families of Portuguese ancestry Clin Genet 88(1) 41-48 https://doi.org/10.1111/cge.12441 PMID: 24916970

8. Kim H and Choi DH (2013) Distribution of BRCA1 and BRCA2 mutations in Asian patients with breast cancer J Breast Cancer 16(4) 357-365 https://doi.org/10.4048/jbc.2013.16.4.357 PMID: 24454456 PMCID: 3893336

9. Rafnar T, Benediktsdottir KR, and Eldon BJ, et al (2004) BRCA2, but not BRCA1, mutations account for familial ovarian cancer in Iceland: a population-based study Eur J Cancer 40(18) 2788-2793 https://doi.org/10.1016/j.ejca.2004.09.008 PMID: 15571962

10. Peixoto A, Santos C, and Rocha P, et al (2009) The c.156_157insAlu BRCA2 rearrangement accounts for more than one-fourth of deleterious BRCA mutations in northern/central Portugal Breast Cancer Res Treat 114(1) 31-38 https://doi.org/10.1007/s10549-008-9978-4 PMID: 18363094

11. Machado PM, Brandão RD, and Cavaco BM, et al (2019) Screening for a BRCA2 rearrangement in high-risk breast/ovarian cancer families: evidence for a founder effect and analysis of the associated phenotypes J Clin Oncol 25(15) 2027-2034 https://doi.org/10.1200/ JCO.2006.06.9443 PMID: 17513806

12. Rebbeck TR, Friebel TM, and Friedman E, et al (2018) Mutational spectrum in a worldwide study of 29,700 families with BRCA1 or BRCA2 mutations Hum Mutat 39(5) 593-620 https://doi.org/10.1002/humu.23406 PMID: 29446198 PMCID: 5903938 
13. Alsop K, Fereday S, and Meldrum C, et al (2012) BRCA mutation frequency and patterns of treatment response in BRCA mutationpositive women with ovarian cancer: a report from the Australian Ovarian Cancer Study Group J Clin Oncol 30(21) 2654-2664 https:// doi.org/10.1200/JCO.2011.39.8545 PMID: 22711857 PMCID: 3413277

14. Ganguly A, Rock MJ, and Prockop DJ (1993) Conformation-sensitive gel electrophoresis for rapid detection of single-base differences in double-stranded PCR products and DNA fragments: evidence for solvent-induced bends in DNA heteroduplexes Proc Natl Acad Sci U S A 90(21) 10325-10329 https://doi.org/10.1073/pnas.90.21.10325 PMID: 8234293 PMCID: 47767

15. Mattocks CJ, Watkins G, and Ward D, et al (2010) Interlaboratory diagnostic validation of conformation-sensitive capillary electrophoresis for mutation scanning Clin Chem 56(4) 593-602 https://doi.org/10.1373/clinchem.2009.135426 PMID: 20167696

16. Hill M (2011) Conformation sensitive gel electrophoresis Methods Mol Biol 688 7-16 https://doi.org/10.1007/978-1-60761-947-5_2 PMID: 20938829

17. Bexiga C, Nejo P, and Oliveira I, et al (2020) Abstract P6-08-17: when BRCA2-breast cancer is more prevalent than BRCA1-breast cancer: prospective follow-up data from a multidisciplinary program Cancer Res 80(4 Supplement) https://doi.org/10.1158/1538-7445. SABCS19-P6-08-17

18. Maistro S, Teixeira N, and Encinas G, et al (2016) Germline mutations in BRCA1 and BRCA2 in epithelial ovarian cancer patients in Brazil BMC Cancer 16(1) 934 https://doi.org/10.1186/s12885-016-2966-x PMID: 27914478 PMCID: 5135756

19. Alemar B, Herzog J, and Netto CBO, et al (2016) Prevalence of Hispanic BRCA1 and BRCA2 mutations among hereditary breast and ovarian cancer patients from Brazil reveals differences among Latin American populations Cancer Genet 209(9) 417-422 https://doi. org/10.1016/j.cancergen.2016.06.008 PMID: 27425403

20. Cotrim DP, Ribeiro ARG, and Paixão D, et al (2019) Prevalence of BRCA1 and BRCA2 pathogenic and likely pathogenic variants in non-selected ovarian carcinoma patients in Brazil BMC Cancer 19(1) 4 https://doi.org/10.1186/s12885-018-5235-3 PMID: 30606148 PMCID: 6319008

21. Rodríguez AO, Llacuachaqui M, and Pardo GG, et al (2019) BRCA1 and BRCA2 mutations among ovarian cancer patients from Colombia Gynecol Oncol 124(2) 236-243 https://doi.org/10.1016/j.ygyno.2011.10.027 PMID: 22044689

22. Blay P, Santamaría I, and Pitiot AS, et al (2013) Mutational analysis of BRCA1 and BRCA2 in hereditary breast and ovarian cancer families from Asturias (Northern Spain) BMC Cancer 13243 https://doi.org/10.1186/1471-2407-13-243 PMID: 23683081 PMCID: 3662577

23. Zhang S, Royer R, and Li S, et al (2011) Frequencies of BRCA1 and BRCA2 mutations among 1,342 unselected patients with invasive ovarian cancer Gynecol Oncol 121 353-357 https://doi.org/10.1016/j.ygyno.2011.01.020 PMID: 21324516

24. Damiola F, Pertesi M, and Oliver J, et al (2014) Rare key functional domain missense substitutions in MRE11A, RAD50, and NBN contribute to breast cancer susceptibility: results from a Breast Cancer Family Registry case-control mutation-screening study Breast Cancer Res 16(3) R58 https://doi.org/10.1186/bcr3669 PMID: 24894818 PMCID: 4229874

25. Walsh T, Casadei S, and Lee MK, et al (2011) Mutations in 12 genes for inherited ovarian, fallopian tube, and peritoneal carcinoma identified by massively parallel sequencing Proc Natl Acad Sci USA 108(44) 18032-18037 https://doi.org/10.1073/pnas.1115052108 PMID: 22006311 PMCID: 3207658

26. Pinto $P$, Paulo $P$, and Santos $C$, et al (2016) Implementation of next-generation sequencing for molecular diagnosis of hereditary breast and ovarian cancer highlights its genetic heterogeneity Breast Cancer Res Treat 159(2) 245-256 https://doi.org/10.1007/s10549-0163948-z PMID: 27553368

27. Bogdanova N, Sokolenko AP, and lyevleva AG, et al (2011) PALB2 mutations in German and Russian patients with bilateral breast cancer Breast Cancer Res Treat 126(2) 545-550 https://doi.org/10.1007/s10549-010-1290-4 PMID: 21165770. PMCID: 3291835 
28. Zhang K, Zhou J, and Zhu X, et al (2017) Germline mutations of PALB2 gene in a sequential series of Chinese patients with breast cancer Breast Cancer Res Treat 166(3) 865-873 https://doi.org/10.1007/s10549-017-4425-z PMID: 28825143

29. Hu C, Hart SN, and Gnanaolivu R, et al (2021) A population-based study of genes previously implicated in breast cancer N Engl J Med 384(5) 440-451 https://doi.org/10.1056/NEJMoa2005936 PMID: 33471974 PMCID: 8127622

30. Breast Cancer Association Consortium, Dorling L, and Carvalho S, et al (2021) Breast cancer risk genes - association analysis in more than 113,000 women N Engl J Med 384(5) 428-439 https://doi.org/10.1056/NEJMoa1913948 PMID: 33471991

31. BRCAexchange database [https://brcaexchange.org/] Date accessed: 21/07/20 